\title{
Treatment options for PNET liver metastases: a systematic review
}

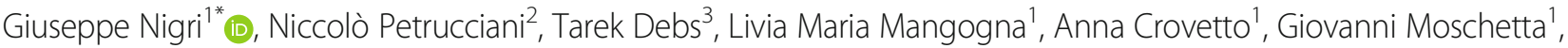 \\ Raffaello Persechino ${ }^{1}$, Paolo Aurello ${ }^{1}$ and Giovanni Ramacciato ${ }^{1}$
}

\begin{abstract}
Background: Pancreatic neuroendocrine tumors (PNETs) are rare pancreatic neoplasms. About $40-80 \%$ of patients with PNET are metastatic at presentation, usually involving the liver (40-93\%). Liver metastasis represents the most significant prognostic factor. The aim of this study is to present an up-to-date review of treatment options for patients with liver metastases from PNETs.
\end{abstract}

Methods: A systematic literature search was performed using the PubMed database to identify all pertinent studies published up to May 2018.

Results: The literature search evaluated all the therapeutic options for patients with liver metastases of PNETs, including surgical treatment, loco-regional therapies, and pharmacological treatment. All the different treatment options showed particular indications in different presentations of liver metastases of PNET. Surgery remains the only potentially curative therapeutic option in patients with PNETs and resectable liver metastases, even if relapse rates are high. Efficacy of medical treatment has increased with advances in targeted therapies, such as everolimus and sunitinib, and the introduction of radiolabeled somatostatin analogs. Several techniques for loco-regional control of metastases are available, including chemo- or radioembolization.

Conclusions: Treatment of patients with PNET metastases should be multidisciplinary and must be personalized according to the features of individual patients and tumors.

\section{Background}

Pancreatic neuroendocrine tumors (PNETs) are rare tumors, representing 1.3 to $10.0 \%$ of all pancreatic tumors. Annual incidence of PNET is estimated to be $3.65 / 10,000$ people per year [1-3]. Due to the recent widespread use of diagnostic techniques, there is a dramatic increase in the incidence of PNETs [4]. No differences in PNET incidence are reported between men and women. Peak of PNET's diagnosis occurs between 30 and 60 years [5]. PNETs may be classified as functioning or non-functioning tumors. Functioning PNETs are characterized by secretion of one or more biologically active peptides, inducing specific clinical syndromes. Secreting products include insulin, gastrin, glucagon, somatostatin, and vasoactive intestinal peptide

\footnotetext{
* Correspondence: giuseppe.nigri@uniroma1.it

${ }^{1}$ Department of Medical and Surgical Science and Translational Medicine, St. Andrea Hospital Rome, Sapienza University of Rome, Via di Grottarossa 1035, 00189 Rome, Italy

Full list of author information is available at the end of the article
}

(VIP). Non-functioning PNETs may secrete peptides, such as chromogranin A and neurotensin, and may be asymptomatic [6]. Diagnosis of non-functioning PNETs is usually late for the absence of specific symptoms; therefore, probability of malignancy is higher if compared with functioning PNETs and reported survival is as low as 30\% [7]. PNETs are also characterized by the expression of somatostatin receptors. They may be a component of several syndromes, such as Von HippelLindau syndrome, multiple endocrine neoplasia syndromes, or neurofibromatosis type I [6]. Metastases are detected at diagnosis in about $40-80 \%$ of patients with PNET [8]. The more frequent sites are the liver (40-93\%), followed by the bone $(12-20 \%)$ and lungs $(8 \%-10 \%)$ [8]. The presence of liver metastases also has a negative impact on the prognosis $[9,10]$, and the extension of PNET liver metastases is correlated to long-term survival $[11,12]$. The development of liver metastasis is related to the histological tumor type and to the site of the primary tumor [13]. Other factors with a strong prognostic impact are as

(C) The Author(s). 2018 Open Access This article is distributed under the terms of the Creative Commons Attribution 4.0 International License (http://creativecommons.org/licenses/by/4.0/), which permits unrestricted use, distribution, and 
follows: size of the primary tumor, mitotic index, vascular and lymphatic invasion, proliferative activity, metabolite serum concentration, and cellular atypias [14]. Treatment of metastatic PNETs is complex and requires multidisciplinary expertise including medical, interventional, and surgical specialties.

Furthermore, multidisciplinary management of metastatic PNETs is in constant evolution. Therefore, it is important to periodically review the recent acquisition, to provide up-to-date and comprehensive data to clinicians. This review, based on a systematic literature search, aims to discuss metastatic PNET's management from clinical, biochemical, and radiological diagnosis to treatment, focusing on all treatment possibilities in a multidisciplinary approach.

\section{Methods}

\section{Search strategy and study selection}

A systematic literature search was performed using the PubMed database, in order to identify all studies published up to May 2018 reporting data on patients treated for liver metastases from pancreatic neuroendocrine tumors (PNETs) undergoing surgical treatment, including liver resection or liver transplantation, interventional procedures, or medical treatment. The following MeSH search terms were used: "liver" OR "hepatic," "metastasis OR metastases," and "pancreatic neuroendocrine tumor" OR "PNET." The "related articles" function was used to broaden the search, and all the abstracts and citations of all returned studies were reviewed. The full text was examined, in case of any doubt after reading the article's abstract. Non-English language studies were excluded. Two authors (NP, LM) examined the articles to establish the inclusion in this review.

\section{Results}

\section{Search results}

Initial search retrieved 10,135 articles. Titles and abstract were analyzed to identify 476 relevant publications. Of them, 116 articles were retained to review the current literature on this topic [1-116]. PRISMA flow diagram is showed in Fig. 1. The majority of them were observational studies. Meta-analyses and review were the second most represented group.

\section{Diagnosis and staging}

The main factors determining the clinical manifestation of PNET liver metastases are the liver tumor load and the degree of endocrine activity. Usually, patients may remain asymptomatic for a long time. Development of carcinoid syndrome is possible, such as abdominal pain or discomfort. Liver malfunction or failure is a rare occurrence, even in the case of extensive liver involvement [15].
Diagnosis is done on the basis of biochemical laboratory examinations, including specific tumor markers, and on radiological imaging.

Plasmatic chromogranin A is a widely accepted tumor marker, used for diagnostic and prognostic purposes and to evaluate the response to treatment. Its specificity and sensitivity depend on tumor type and volume [16]. 5 -Hydroxyindoleacetic acid is a urinary metabolite of serotonin, which may be increased in patients with metastatic PNET, and it is used for diagnosis and follow-up [17]. Other biochemical markers are less used in clinical practice, including urine serotonin, synaptophysin, neuron-specific enolase, parathyroid hormonerelated protein, calcitonin, pancreatic polypeptide, and human chorionic gonadotropin [18]. On the other hand, functioning tumors secrete hormones related to a specific clinical syndrome, such as insulin (insulinoma), glucagon (glucagonoma, confirmed by serum glucagon level $>1000 \mathrm{pg} / \mathrm{mL}$ ), gastrin (elevated serum gastrin and gastric acids), and vasoactive intestinal polypeptide (vipoma, VIP values $>200 \mathrm{pg} / \mathrm{mL}$ ) [19-21].

Somatostatin receptor scintigraphy is frequently used for PNET imaging. Advantages include the acquisition of whole-body images with possible visualization of the primary tumor and metastases, and the possibility to identify the patients who are candidates for somatostatin receptor-based radiotherapy [22].

Positron emission tomography (PET) with DOTATOC or DOTANOC associated with the positron emitter Gallium 68 allows even better sensitivity (up to 30\% higher than standard imaging) [23].

CT scan has wide diffusion and is associated with sensitivity rates up to $94-100 \%$ [24], especially if combined with PET [25]. Magnetic resonance imaging is also used in the staging and evaluation of disease progression, for its ability to detect lesions in the liver, combined with reduction of excessive radiation burden [26].

Several staging systems exist for PNET classification. The WHO, European Neuroendocrine Tumor Society (ENETS), and American Joint Committee on Cancer (AJCC) have proposed each a staging system [27-29]. The WHO classification is based on cellular proliferation (measured as mitotic count and Ki-67 expression), as shown in Table 1 [27]. The ENETS staging system (Table 2) is based on TNM classification [28], and the AJCC staging system (reported in Table 3) is developed from the TNM staging system for pancreatic adenocarcinoma [29].

\section{Treatment options for metastatic PNETs}

The therapeutic options for patients with liver metastases from pancreatic neuroendocrine tumors include surgical treatment, loco-regional therapies, and pharmacological treatment. The decision of the treatment strategy is based 
PRISMA 2009 Flow Diagram

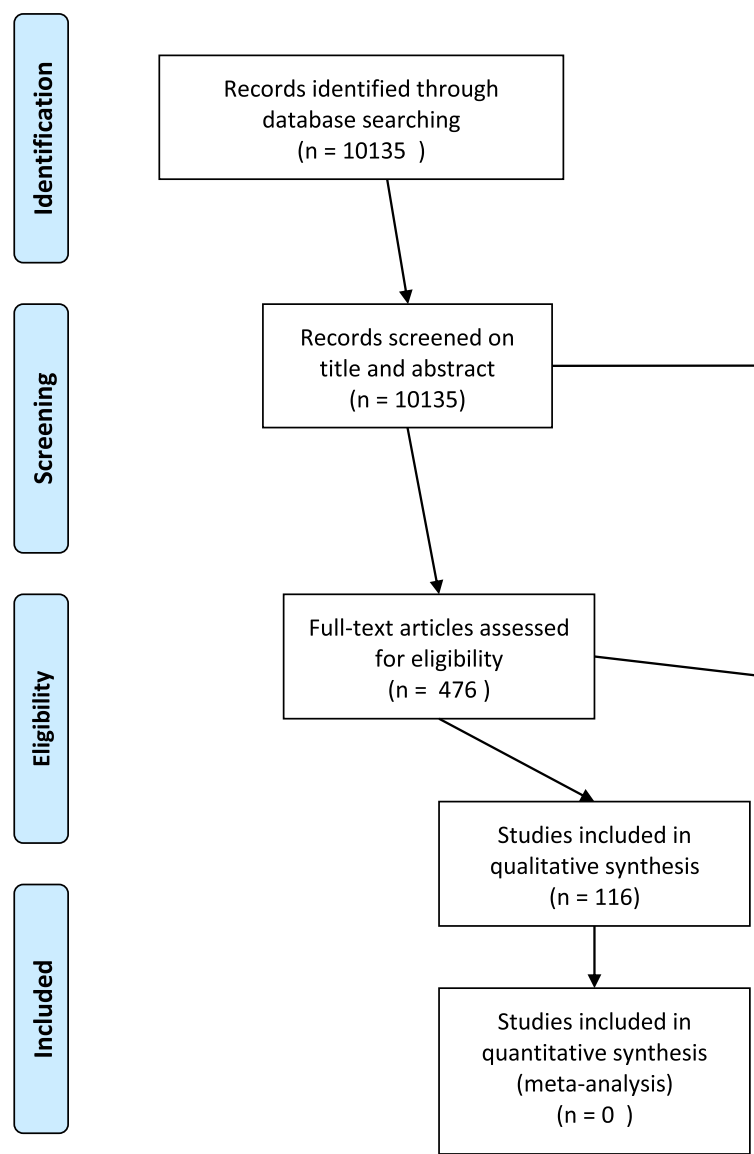

Records excluded $(n=9659)$

- non pertinent to review question

Full-text articles excluded, with reasons $(n=360)$

- Non relevant study desing non pertinent to review question

Fig. 1 PRISMA diagram showing the systematic search results

on the analysis of patient performance status and comorbidities, on accurate tumor staging, and on evaluation of prognostic factors. Surgery represents the only potentially curative therapy when the disease is completely resectable. In patients with advanced and unresectable disease, however, the therapeutic goal is lengthening survival with the best possible quality of life and palliation of symptoms, using a multidisciplinary approach.

\section{Liver surgery for pancreatic neuroendocrine liver metastases}

Surgery remains the treatment of choice in selected patients with PNETs and resectable liver metastases, because it may provide cure. Liver resection for neuroendocrine metastases is associated to long-term survival advantages and disease control [30, 31]. Surgery may have either curative intent, when complete resection is possible, or palliative intent, when the majority of the tumor burden is removed to control the symptoms of the disease. Due to the rarity of the disease, the majority of published articles on surgical treatments of liver metastases from neuroendocrine tumors report data on neuroendocrine metastases from several primary sites (e.g., GEP-NET metastases).

\section{Potentially curative surgery}

Potentially curative surgery is possible in only $10-25 \%$ of patients with liver metastases [32]. Bilobar metastases may be treated with two-step resections, and preoperative portal vein embolization may be used to induce hypertrophy of the left liver lobe, as in colorectal liver metastases [33]. Concurrent or staged resection of the primary lesion and liver metastases may be considered, if surgery can remove most of the metastatic tumor volume (>90\%). Criteria helping to select patients for surgery include the presence of well-differentiated G1/ G2 tumors, absence of distant lymph node metastasis, absence of extrahepatic metastasis, absence of diffuse peritoneal metastasis, and absence of right cardiac dysfunction [34]. 
Table 1 WHO grading system for PNETs [27]

\begin{tabular}{llll}
\hline & Grade 1 (G1) & Grade 2 (G2) & Grade 3 (G3) \\
\hline Ki-67 index & $<3 \%$ & $3-20 \%$ & $>20 \%$ \\
Mitotic count & $<2 / 10 \mathrm{HPF}$ & $2-20 / 10 \mathrm{HPF}$ & $>20 / 10 \mathrm{HPF}$ \\
Differentiation & Well differentiated & Moderately differentiated & Poorly differentiated
\end{tabular}

WHO World Health Organization, PNETs pancreatic neuroendocrine tumors, HPF high-power field

Unfortunately, tumor relapse in the first 2 years after resection is reported in the majority of patients [35], and a relapse rate of up to $80 \%$ at 5 years has been shown [36-50]. Despite the elevated percentage of tumor recurrence, 5 -year survival rates approach $85 \%$, which is in favor of an aggressive surgical approach. Morbidity and mortality of liver resection are acceptable with the advancement in preoperative management and surgical techniques, and are comparable to liver resection for other diseases [36-51].

No randomized trials have compared the results of liver resection to other non-surgical treatments for PNET liver metastases [52]. However, retrospective comparisons of the outcomes of patients treated with medical therapies or palliative care or surgery highlight the advantages of surgical treatment. Survival outcomes of curative surgery are better than those of loco-regional therapies, such as liver chemoembolization, as reported by Elias et al., detecting a 5 -year survival rate of $71 \%$ for 47 patients who underwent partial hepatectomy versus $31 \%$ for 65 patients treated with chemoembolization [41]. Furthermore, Tao et al. demonstrated that debulking surgery improves the effect of the subsequent loco-regional treatment [49].

The presence of a single liver metastasis is associated with better survival, as shown by Frilling et al. [32]. In cases of synchronous metastases, simultaneous resection of the primitive tumor and hepatectomy has been reported, with acceptable postoperative morbi-mortality. Sarmiento et al. treated 23 patients who underwent synchronous pancreatic and liver resection. Postoperative

Table 2 ENETS staging system for PNET [28]

\begin{tabular}{llll}
\hline Stage & T & N & M \\
\hline I & T1 & No & M0 \\
IIA & T2 & No & M0 \\
IIB & T3 & No & M0 \\
IIIA & T4 & No & M0 \\
IIIB & Any T & N1 & M0 \\
IV & Any T & Any N & M1
\end{tabular}

ENETS European Neuroendocrine Tumor Society, PNET pancreatic

neuroendocrine tumors, $T 1$ tumors $<2 \mathrm{~cm}$ limited to the pancreas, $T 22-4 \mathrm{~cm}$ limited to the pancreas, $T 3>4 \mathrm{~cm}$ limited to the pancreas or invading the duodenum or common bile duct, $T 4$ tumor invading adjacent structures or large vessels, NO no regional lymph node metastases, N1 regional lymph node metastases, $M 0$ no distant metastases, $M 1$ distant metastases mortality was $0 \%$, the major complication rate $18 \%$, and the 5 -year survival was as high as $71 \%$ [42]. Bonney et al. showed comparable results, with morbidity of $25 \%$, one death in the postoperative period, and a 5-year survival of $70 \%[48]$.

\section{Cytoreductive surgery}

Cytoreductive surgery in patients with PNET liver metastases aims to increase survival, control symptoms, and improve quality of life. Cytoreductive liver resections are indicated in patients with symptoms not controllable with medical or hormonal treatment. It consists of resection of more than $90 \%$ of the tumor mass [53, 54]. Recently, Morgan et al. proposed a threshold of $>70 \%$, with the argument that postoperative results are comparable between debulking $>70,>90$, and $100 \%$ [55]. Reduction in tumor volume may reduce the immunosuppressive effects of the tumor and decrease the probability of development of further metastases. Surgical debulking is efficient for the symptoms in the majority of patients with functioning PNETs $[44-47,56]$. Combined approaches including aggressive surgical resection, ablative therapies, and chemotherapy may be employed to obtain cytoreduction of the tumor [57].

Symptomatic benefits are achieved in $80-90 \%$ of patients submitted to curative liver resections [12, 42, 54]. The mean duration of the response to the surgical debulking is correlated with the amount of tumor removed and to the normalization of tumor markers [12]. Recurrence of symptoms occurs in the first 5 years after

Table 3 AJCC staging system for PNETs (7th edition, 2010) [29]

\begin{tabular}{llll}
\hline Stage & T & N & M \\
\hline 0 & Tis & No & M0 \\
IA & T1 & No & M0 \\
IB & T2 & No & M0 \\
IIA & T3 & No & M0 \\
IIB & T1-3 & N1 & M0 \\
III & T4 & Any N & M0 \\
IV & Any T & Any N & M1
\end{tabular}

AJCC American Joint Committee on Cancer, PNET pancreatic neuroendocrine tumors, $T 1<2 \mathrm{~cm}$ limited to the pancreas, $T 2>2 \mathrm{~cm}$ limited to the pancreas, $T 3$ tumor extends beyond the pancreas but not involving the celiac axis or SMA, T4 tumor involves celiac axis or SMA, NO no regional lymph node metastases, $N 1$ regional lymph node metastases, $M 0$ no distant metastases, $M 1$ distant metastases 
surgery in the majority of patients [42]. Reported rates of complications and mortality are considered acceptable $[12,42,44-46,58-60]$. If $>75 \%$ of the liver parenchyma is involved, prognosis is considered unfavorable and surgical treatment should be avoided [43].

\section{Liver transplantation}

Liver transplantation represents a potentially curative treatment for liver metastases from PNETs. Early results are promising, and future development of this strategy is possible. Orthotropic liver transplantation (OLT) has been proposed for PNETs for two reasons: the less-aggressive biological behavior of neuroendocrine metastases compared to other metastases and the low percentage of patients with PNET liver metastases candidates for R0 liver resections $[8,61]$. However, this indication is restricted because of the lack of donors and the perplexity in allocation of organs to oncological patients. Furthermore, the first studies on liver transplantation for metastatic neuroendocrine tumors were not concordant and reported mediocre results. This was due in part to the lack of valid and homogeneous selection criteria [61-67].

Liver transplantation is considered reasonable if expected overall survival is more than $70 \%$ at 5 years and disease-free survival is more than $50 \%$ [8]. The best candidates in this setting are young patients $(<50$ years old), with no extrahepatic lesions, well-differentiated tumors, and low levels of Ki-67. Mazzaferro et al. proposed the following inclusion criteria [8]: diagnosis of low-grade NET confirmed by histological examination (with low expression of Ki-67), location of the primary tumor in an anatomic area tributary to the portal vein, primary tumor already resected with clear margins, < $50 \%$ of liver involvement, stable disease during 6 months before OLT, and age $<55$ years. Recently, a comprehensive review showed encouraging 5-year survival after OLT for NET, but a high recurrence rate [68]. So at present, liver transplantation does not represent routine care in this setting and is considered investigational and allowed in the setting of clinical studies [69].

Another debated point is the indication for primary tumor resection in patients with unresectable metastatic disease. Recent retrospective studies [70] and a metaanalysis showed that the palliative resection of the primary tumor in patients with PNETs and unresectable liver metastases may increase long-term survival. The meta-analysis by Zhou and colleagues included 10 studies, with a total of 1226 patients undergoing primary tumor resection and 1623 patients who did not have surgery [71]. The results of the meta-analysis showed a significantly longer survival in patients who had surgical resection of the primary tumor (at 5 years, 35.7-83\% surviving patients in the surgical group versus $5.4-50 \%$ in the non-surgical group) [71].

\section{Liver-directed therapies}

Liver-directed therapies used to treat PNET metastases include radiofrequency ablation (RFA), cryoablation, alkalization, transarterial embolization (TAE), and transarterial chemoembolization (TACE) [72].

\section{Ablative therapies}

RFA is a safe technique, generally used to treat unresectable metastases smaller than $5 \mathrm{~cm}$. Associated morbidity is low and mainly consists in bleeding and abscess formation [73]. RFA is effective to treat symptoms related to liver metastases and hormone secretion, even if the tumor size represents a limiting factor. RFA is less useful for tumors $>5 \mathrm{~cm}$, even if repeat ablation sessions are possible [37]. The location of the lesion should be considered, because RFA may be contraindicated for liver metastases near to vital structures or at the liver surface. Cryotherapy is another suitable option, and percutaneous ethanol injection is an alternative in cases where tumors are close to vital structures or vessels [74].

\section{Hepatic arterial embolization}

The rationale of hepatic transarterial embolization is that neuroendocrine metastases receive most of their blood supply from the hepatic artery, whereas normal liver parenchyma gets $75 \%$ of its blood supply from the portal vein flow [75]. Both TAE and TACE effectively reduce tumor size and improve patients' symptoms. No randomized studies comparing the two techniques have been published nor studies comparing embolization techniques with cytoreductive surgery in the palliative segment. Embolization is not associated with risks of tumor dissemination (this is an advantage compared to RFA). During TAE, embolization is performed using lipiodol, gem foam particles, polyvinyl alcohol foam, or bland microspheres, whereas for TACE, chemotherapeutic agents are added, leading to an intra-tumoral drug concentration over 20 times greater than those obtained with systemic administration. Furthermore, both provoke tumor ischemia. Commonly used drugs are doxorubicin, melphalan, and streptozocin. Minor side effects of the procedure are fever, leukocytosis, abdominal pain, and liver cytolysis.

Morbidity rate is low, even if serious complications, such as liver abscess, gallbladder necrosis, bowel ischemia, pleural effusion, and hepatic failure, have been reported [76]. Tumor response is objectivized in 25$86 \%$ of cases, and the duration of the response ranges from 6 to 45 months [77-79]. In a recent series, clinical improvement and tumor response were observed in $95 \%$ of patients, with median time to tumor progression of $14 \pm 16$ months and median overall survival of $22 \pm$ 18 months [80]. 
Both TAE and TACE are considered for palliation in unresectable tumors, especially for functioning tumors with symptoms not controlled by medical therapy. Contraindications of TAE and TACE include portal vein occlusion, insufficient liver reserve, and poor performance status. In patients with previous pancreaticoduodenectomy, transarterial therapies are generally contraindicated, due to higher risks of post-procedure morbidity. Liver-directed therapies may also be proposed in patients with extrahepatic metastases to control liver disease and symptoms [80-83].

Selective internal radiotherapy (SIRT) consists of embolization with 90Yttrium microsphere, a beta-emitter that results in tissue penetration of $2.5 \mathrm{~mm}$. Published data on SIRT show a response rate of $55 \%$ and stabilization of the disease in $32 \%$ of cases [84-87]. More recently, an overall disease control rate of $88.9 \%$ at 3 months after therapy has been demonstrated, confirming its effectiveness in treating unresectable PNET liver metastases [30]. SIRT is contraindicated in cases of aberrant vessels with shunt to the gastrointestinal tract, compromised portal veins, and inadequate liver functional reserve to avoid potentially serious complications.

\section{Medical therapy}

Medical therapy is indicated for advanced unresectable PNETs and includes drugs acting on hormone receptors, conventional chemotherapy, and molecular target therapy [88].

Somatostatin analogs (SSAs) act on somatostatin receptors and are effective in controlling hormonal secretion and tumor growth. Either functioning or non-functioning PNETs express at least one of the five subtypes of somatostatin receptor (SSTR). Different SSAs have specific affinity for different SSTRs [89]. Octreotide and lanreotide have high affinity for SSTR2 and bind to SSTR5, whereas the recent analog pasireotide binds with high affinity to SSTR1, SSTR2, SSTR3, and SSTR5 [89, 90]. Several studies and a randomized controlled trial advocate the use of SSAs to control tumor growth and symptoms in this setting $[89,91,92]$. The randomized controlled trial by Rinke et al. demonstrated that long-acting octreotide is efficacious on both functioning and non-functioning tumors, with a $66.7 \%$ reduction in the risk of disease progression in treated patients compared to patients taking a placebo [92]. However, these results referred to a specific setting of patients with limited liver involvement $(\leq 10 \%)$ and already resected primary tumors. Further randomized trials to confirm these data in other patient categories are needed. The CLARINET (Controlled Study on Lanreotide Antiproliferative Response in NETs) study is an ongoing trial, which aims to evaluate the efficacy of lanreotide in patients with well or moderately differentiated, non-functioning NETs with Ki-67\% expression < 10\% [93]. A number of other previous studies have advocated for the efficacy of SSAs on PNETs, with tumor stabilization reported in $40-80 \%$ of patients and objective tumor response (demonstrated by reduction of tumor volume) in about 10\% of patients [94-96]. If treatment with SSAs at standard dose fails, management options include shortening of SSA administration intervals or augmentation of SSA dosage. For patients with progressing tumors, administration of SSAs every 21 days was compared to administration every 28 days, demonstrating a longer time to progression, better symptom control, and reduction in the serum level of tumor markers in the group with the shorter interval of administration [97]. SSAs are well tolerated and have generally mild side effects. Long-term side effects include gallbladder lithiasis (1\%), glucose intolerance or diabetes, and steatorrhea [96].

Alpha-interferon may be associated with somatostatin analogs for palliation or hormonal symptoms, with tumor stabilization occurring in $30-80 \%$ of patients. Reduction of tumor volume occurs only in a small percentage of patients [98]. Side effects are frequent and include flu-like symptoms (80-90\%), anorexia, weight loss, fatigue, bone marrow or liver toxicity, and autoimmune disorders.

Systemic chemotherapy is only indicated for advanced and unresectable PNETs and may consist in the administration of various cytotoxic agents, such as streptozotocin, cisplatin, dacarbazine, doxorubicin, and 5-fluorouracil [99]. The efficacy of the combination of streptozotocin with 5-fluorouracil (5-FU) and/or epirubicin in treating G1/G2 pNENs has been demonstrated, with a reported objective response rate of $20-45 \%[100,101]$. Alternative options include temozolomide alone or in combination with capecitabine, leading to a partial response rate of $70 \%$, median progression-free survival (PFS) of 18 months, and 2-year survival of $92 \%$ in cases of metastatic, well-differentiated PNETs [102]. For high-grade tumors with poor differentiation, platinum-based regimes are preferred. Response rates of $42-67 \%$ have been obtained combining cisplatin and etoposide [103]. Saif et al. suggested the use of capecitabine/ temozolomide (CAPTEM) regimen in patients with failure of the previous therapy [104].

\section{Targeted therapies}

Recent advancements in comprehension of the pathogenesis and molecular mechanisms of PNETs have allowed the development and introduction of novel targeted therapies in the clinical practice. The mTOR protein is a serine/threonine kinase, and a key component of a cellular pathway playing an important role in the regulation of cell growth and proliferation. mTOR is upregulated in several tumors, including PNETs [105]. Everolimus is an mTOR inhibitor that has shown efficacy in phase II and phase III studies in patients with PNETs [106]. The RADIANT3 study randomized patients with advanced PNET into two groups: patients 
receiving everolimus (10 $\mathrm{mg}$ per day) (group 1 ) and patients receiving a placebo (group 2). Patients treated with everolimus had significantly longer PFS (11 versus 4.6 months) than patients receiving placebo [107]. Side effects include stomatitis, rash, fatigue, diarrhea, hyperglycemia, and hematological and pneumological effects.

Sunitinib is an inhibitor of the tyrosine kinases PDGFR, VEGFR-1, VEGFR-2, c-KIT, and FLIT3 [108, 109]. The rationale for its use in the treatment of PNETs is the frequent overexpression of VEGF or VEGFR by these tumors. A phase III study comparing sunitinib to a placebo has shown a response rate of $9.3 \%$ and an increased PFS of 11.1 months in the group treated with sunitinib (versus PFS of 5.5 months in the placebo group) [110]. Side effects of sunitinib include diarrhea, nausea, vomiting, asthenia, fatigue, hypertension, and neutropenia. Raymond et al. reported a partial tumor response in $42 \%$ of patients and stable disease in $33 \%$ of patients after treatment with $37.5 \mathrm{mg} /$ day of sunitinib [110].

Radiolabeled somatostatin analogs represent a new treatment option in patients with strong radiotrace uptake on SRS [111]. Peptide receptor radionuclide therapy (PRRT) with radiolabeled SSAs allows administration of targeted radiotherapy to the tumor tissue and its metastases [112]. The most used radiolabels are 90Yttrium, a high-energy beta-particle emitter, and 177Lutetium, which emits beta particles and gamma rays. Even if complete tumor response is rare with this treatment $(0-6 \%)$, results are encouraging, with partial tumor regression in $7-37 \%$ of patients and stabilization in $42-86 \%$ using 90Yttriumlabeled SSAs [112-114]. 177Lutetium octreotate was used on 510 patients, $40 \%$ of whom had PNETs, and partial response was observed in $28 \%$ of cases, with stabilization of the disease in $35 \%[115,116]$. PRRT is a promising therapeutic option, even if still investigational.

\section{Conclusions}

Therapeutic options for patients with liver metastases from pancreatic neuroendocrine tumors include surgery, loco-regional therapies, and medical therapies. Surgery represents the only potentially curative treatment and should be proposed for resectable patients, even if relapse rates are high. Efficacy of medical treatment has increased with advances in targeted therapies, such as everolimus and sunitinib, and with the introduction of radiolabeled somatostatin analogs. Several techniques for loco-regional control of metastases are available, including chemo- or radioembolization. Treatment of patients with pancreatic neuroendocrine metastases should be multidisciplinary, must be personalized according to the features of individual patients and tumors, and should take into account all possible options in order to provide the best possible results in terms of survival and quality of life.

\section{Abbreviations}

5-FU: 5-Fluororacil; PFS: Progression-free survival; PNET: Pancreatic neuroendocrine tumor; PRRT: Peptide receptor radionuclide therapy; RFA: Radiofrequency ablation; SSAs: Somatostatin analogs; SSTR: Somatostatin receptor; TACE: Transarterial chemoembolization; TAE: Transarterial embolization; SIRT: Selective internal radiotherapy; OLT: Orthotropic liver transplantation

\section{Authors' contributions \\ GN, NP, TD, and GR made substantial contribution to the conception and design, acquisition of data, and analysis and interpretation of data and have been involved in drafting the manuscript and revising it critically for important intellectual content. LM, AC, GM, RP, and PA made substantial contribution to the acquisition of data and have been involved in revising the manuscript critically for important intellectual content. GN, NP, TD, GR, LM, AC, GM, RP, and PA give final approval of the version to be published, take public responsibility for appropriate portions of the content, and agree to be accountable for all aspects of the work in ensuring that questions related to the accuracy or integrity of any part of the work are appropriately investigated and resolved. All authors read and approved the final manuscript.}

Ethics approval and consent to participate

Not applicable.

Consent for publication

Not applicable.

\section{Competing interests}

The authors declare that they have no competing interests.

\section{Publisher's Note}

Springer Nature remains neutral with regard to jurisdictional claims in published maps and institutional affiliations.

\section{Author details}

'Department of Medical and Surgical Science and Translational Medicine, St. Andrea Hospital Rome, Sapienza University of Rome, Via di Grottarossa 1035, 00189 Rome, Italy. ${ }^{2}$ Digestive Surgery, Hepatobiliopancreatic Surgery and Liver Transplantation, UPEC University, Henri Mondor Hospital, Creteil, France. ${ }^{3}$ Department of Digestive Surgery and Liver Transplantation, Nice University Hospital, Nice, France.

Received: 11 January 2018 Accepted: 5 July 2018

Published online: 14 July 2018

References

1. Frilling A, Modlin IM, Kidd M, Russell C, Breitenstein S, Salem R, Kwekkeboom D, et al. Recommendations for management of patients with neuroendocrine liver metastases. Lancet Oncol. 2014;15:e8-21.

2. Lawrence B, Gustafsson BI, Chan A, Svejda B, Kidd M, Modlin IM. The epidemiology of gastroenteropancreatic neuroendocrine tumors. Endocrinol Metab Clin N Am. 2011;40:1-18.

3. Sandvik OM, Soreide K, Gudlaugsson E, Kvaloy JT, Soreide JA. Epidemiology and classification of gastroenteropancreatic neuroendocrine neoplasms using current coding criteria. Br J Surg. 2016;103:226-32.

4. Vagefi PA, Razo O, Deshpande V, McGrath DJ, Lauwers GY, Thayer SP, et al. Evolving patterns in the detection and outcomes of pancreatic neuroendocrine neoplasms: the Massachusetts General Hospital experience from 1977 to 2005. Arch Surg. 2007;142:347-54.

5. Rindi G, Capella C, Solcia E. Introduction to a revised clinicopathological classification of neuroendocrine tumors of the gastroenteropancreatic tract. Q J Nucl Med. 2000;44:13-21.

6. Cheslyn-Curtis S, Sitaram V, Williamson RC. Management of non-functioning neuroendocrine tumours of the pancreas. Br J Surg. 1993;80:625-7.

7. Eriksson B, Oberg K. Neuroendocrine tumours of the pancreas. Br J Surg. 2000;87:129-31.

8. Mazzaferro V, Pulvirenti A, Coppa J. Neuroendocrine tumors metastatic to the liver: how to select patients for liver transplantation? J Hepatol. 2007:47:460-6. 
9. Norton JA. Endocrine tumours of the gastrointestinal tract. Surgical treatment of neuroendocrine metastases. Best Pract Res Clin Gastroenterol. 2005;19:577-83.

10. Madeira I, Terris B, Voss M, Denys A, Sauvanet A, Flejou JF, et al. Prognostic factors in patients with endocrine tumours of the duodenopancreatic area. Gut. 1998:43:422-7.

11. Yu F, Venzon DJ, Serrano J, Goebel SU, Doppman JL, Gibril F, et al. Prospective study of the clinical course, prognostic factors, causes of death, and survival in patients with long-standing Zollinger-Ellison syndrome. J Clin Oncol. 1999;17:615-30.

12. Que FG, Nagorney DM, Batts KP, Linz LJ, Kvols LK. Hepatic resection for metastatic neuroendocrine carcinomas. Am J Surg. 1995;10:36-43.

13. Maithel SK, Fong Y. Hepatic ablation for neuroendocrine tumor metastases. J Surg Oncol. 2009;100:635-8.

14. Frilling A, Sotiropoulos GC, Li J, Kornasiewicz O, Plöckinger U. Multimodal management of neuroendocrine liver metastases. HPB (Oxford). 2010;12:361-79.

15. Rossi RE, Massironi S, Conte D, Peracchi M. Therapy for metastatic pancreatic neuroendocrine tumors. Ann Transl Med. 2014;2:8.

16. Singh S, Law C. Chromogranin A: a sensitive biomarker for the detection and post-treatment monitoring of gastroenteropancreatic neuroendocrine tumors. Expert Rev Gastroenterol Hepatol. 2012:6:313-34.

17. Kanakis G, Kaltsas G. Biochemical markers for gastroenteropancreatic neuroendocrine tumours (GEP-NETs). Best Pract Res Clin Gastroenterol. 2012;26:791-802.

18. Ardill JE, Erikkson B. The importance of the measurement of circulating markers in patients with neuroendocrine tumours of the pancreas and gut. Endocr Relat Cancer. 2003;10:459-62.

19. Ro C, Chai W, Yu VE, Yu R. Pancreatic neuroendocrine tumors: biology, diagnosis, and treatment. Chin J Cancer. 2013;32:312-24.

20. O'Grady HL, Conlon KC. Pancreatic neuroendocrine tumours. Eur J Surg Oncol. 2008;34:324-32.

21. Xiang G, Liu X, Tan C, Zhang H, Mai G, Zheng Z. Diagnosis and treatment of VIPoma: a case report and literature review in China. Pancreas. 2012;41:806-7.

22. Diakatou E, Alexandraki Kl, Tsolakis AV, Kontogeorgos G, Chatzellis E, Leont A, et al. Somatostatin and dopamine receptor expression in neuroendocrin neoplasms: correlation of immunohistochemical findings with somatostatin receptor scintigraphy visual scores. Clin Endocrinol. 2015;83:420-8.

23. Tan TH, Lee BN, Hassan SZ. Diagnostic value of (68)Ga-DOTATATE PET/CT in liver metastases of neuroendocrine tumours of unknown origin. Nucl Med Mol Imaging. 2014;48:212-5.

24. Ng CS, Hobbs BP, Chandler AG, Anderson EF, Herron DH, Charnsangavej C, et al. Metastases to the liver from neuroendocrine tumors: effect of duration of scan acquisition on CT perfusion values. Radiology. 2013;269:758-67.

25. Ambrosini V, Morigi JJ, Nanni C, Castellucci P, Fanti S. Current status of PET imaging of neuroendocrine tumors ([18F]FDOPA, [68Ga]tracers, [11C]/[18F]HTP). Q J Nucl Med Mol Imaging. 2015:59:58-69.

26. Armbruster M, Zech CJ, Sourbron S, Ceelen F, Auernhammer CJ, Rist C, et al. Diagnostic accuracy of dynamic gadoxetic-acid-enhanced MRI and PET/CT compared in patients with liver metastases from neuroendocrine neoplasms. J Magn Reson Imaging. 2014;40:457-66.

27. Klimsta DS, Armold R, Capella C, et al. Neuroendocrine neoplasms of the pancreas. In: Bosman F, Carneiro F, Hruban RH, et al., editors. WHO classification of tumours of the digestive system. Lyon: IARC Press; 2010. p. 322-6.

28. Rindi G, Kloppel G, Alhman H, Caplin M, Couvelard A, de Herder WW, et al TNM staging of foregut (neuro)endocrine tumors: a consensus proposal including a grading system. Virchows Arch. 2006;449:395-401.

29. Exocrine and Endocrine Pancreas. AJCC Cancer Staging Manual. New York: Springer; 2010. p. 241-9.

30. Jia Z, Paz-Fumagalli R, Frey G, Sella DM, McKinney JM, Wang W. Singleinstitution experience of radioembolization with yttrium-90 microspheres for unresectable metastatic neuroendocrine liver tumors. J Gastroenterol Hepatol. 2017;32:1617-23.

31. Hodul PJ, Strosberg JR, Kvols LK. Aggressive surgical resection in the management of pancreatic neuroendocrine tumors: when is it indicated? Cancer Control. 2008;15:314-21.

32. Frilling A, Li J, Malamutmann E, Schmid KW, Schmid KW, Bockisch A Broelsch CE. Treatment of liver metastases from neuroendocrine tumours in relation to the extent of hepatic disease. Br J Surg. 2009;96:175-84.

33. Alagusundaramoorthy SS, Gedaly R. Role of surgery and transplantation in the treatment of hepatic metastases from neuroendocrine tumor. World J Gastroenterol. 2014;20:14348-58.
34. Chen X, Ren H, Chi Y, He S, Huang Z, Hu X, Zhao H. Resection of postoperative liver metastasis from pancreatic neuroendocrine tumors: report of one case. Transl Gastroenterol Hepatol. 2016;1:47.

35. Gomez D, Malik HZ, Al-Mukthar A, Menon KV, Toogood GJ, Lodge JP, et al Hepatic resection for metastatic gastrointestinal and pancreatic neuroendocrine tumours: outcome and prognostic predictors. HPB (Oxford). 2007:9:345-51.

36. Mayo SC, de Jong MC, Pulitano C, Clary BM, Reddy SK, Gamblin TC, et al. Surgical management of hepatic neuroendocrine tumor metastasis: results from an international multi-institutional analysis. Ann Surg Oncol. 2010;17:3129-36.

37. Eriksson J, Stålberg P, Nilsson A, Krause J, Lundberg C, Skogseid B, et al. Surgery and radiofrequency ablation for treatment of liver metastases from midgut and foregut carcinoids and endocrine pancreatic tumors. World J Surg. 2008;32:930-8.

38. Elias D, Goéré D, Leroux G, Dromain C, Leboulleux S, de Baere T, et al. Combined liver surgery and RFA for patients with gastroenteropancreatic endocrine tumors presenting with more than 15 metastases to the liver. Eur J Surg Oncol. 2009;35:1092-7.

39. Abood GJ, Go A, Malhotra D, Shoup M. The surgical and systemic management of neuroendocrine tumors of the pancreas. Surg Clin North Am. 2009:89:249-66.

40. Musunuru S, Chen H, Rajpal S, Stephani N, McDermott JC, Holen K, et al. Metastatic neuroendocrine hepatic tumors: resection improves survival. Arch Surg. 2006;141:1000-4.

41. Elias D, Lasser P, Ducreux M, Duvillard P, Ouellet JF, Dromain C, et al. Liver resection (and associated extrahepatic resections) for metastatic welldifferentiated endocrine tumors: a 15-year single center prospective study. Surgery. 2003;133:375-82.

42. Sarmiento JM, Que FG, Grant CS, Thompson GB, Farnell MB, Nagorney DM. Concurrent resections of pancreatic islet cell cancers with synchronous hepatic metastases: outcomes of an aggressive approach. Surgery. 2002;132:976-82.

43. Chamberlain RS, Canes D, Brown KT, Saltz L, Jarnagin W, Fong Y, et al. Hepatic neuroendocrine metastases: does intervention alter outcomes? J Am Coll Surg. 2000;190:432-45.

44. Chen H, Hardacre JM, Uzar A, Cameron JL, Choti MA. Isolated liver metastases from neuroendocrine tumors: does resection prolong survival? J Am Coll Surg. 1998;187:88-93.

45. Nave $H$, Mossinger $E$, Feist $H$, Lang $H$, Raab $H$. Surgery as primary treatment in patients with liver metastases from carcinoid tumors: a retrospective, unicentric study over 13 years. Surgery. 2001;129:170-5.

46. Jaeck D, Oussoultzoglou E, Bachellier P, Lemarque P, Weber JC, Nakano H, et al. Hepatic metastases of gastroenteropancreatic neuroendocrine tumors: safe hepatic surgery. World J Surg. 2001;25:689-92.

47. Norton JA, Warren RS, Kelly MG, Zuraek MB, Jensen RT. Aggressive surgery for metastatic liver neuroendocrine tumors. Surgery. 2003;134:1057-65.

48. Bonney GK, Gomez D, Rahman SH, Verbeke CS, Prasad KR, Toogood GJ, et al. Results following surgical resection for malignant pancreatic neuroendocrine tumours. A single institutional experience. JOP. 2008:9:19-25.

49. Tao L, Xiu D, Sadula A, Ye C, Chen Q, Wang H, et al. Surgical resection of primary tumor improves survival of pancreatic neuroendocrine tumor with liver metastases. Oncotarget. 2017;8:79785-92.

50. Watzka FM, Fottner C, Miederer M, Schad A, Weber MM, Otto G, et al. Surgical therapy of neuroendocrine neoplasm with hepatic metastasis: patient selection and prognosis. Langenbecks Arch Surg. 2015;400:349-58.

51. Genc CG, Klümpen HJ, van Oijen MGH, van Eijck CHJ, Nieveen van Dijkum EJM. A nationwide population-based study on the survival of patients with pancreatic neuroendocrine tumors in the Netherlands. World J Surg. 2018;42:490-7.

52. Du S, Wang Z, Sang $X$, Lu X, Zheng $Y, X u$ H, et al. Surgical resection improves the outcome of the patients with neuroendocrine tumor liver metastases: large data from Asia. Medicine (Baltimore). 2015;94:e388.

53. Gurusamy KS, Ramamoorthy R, Sharma D, Davidson BR. Liver resection versus other treatments for neuroendocrine tumours in patients with resectableliver metastases. Cochrane Database Syst Rev. 2009:(2):CD007060.

54. Chung MH, Pisegna J, Spirt M, Giuliano AE, Ye W, Ramming KP, et al. Hepatic cytoreduction followed by a novel long-acting somatostatin analog: a paradigm for intractable neuroendocrine tumors metastatic to the liver. Surgery. 2001;130:954-62.

55. Morgan RE, Pommier SJ, Pommier RF. Expanded criteria for debulking of liver metastasis also apply to pancreatic neuroendocrine tumors. Surgery. 2018;163:218-25. 
56. Sarmiento JM, Heywood G, Rubin J, Ilstrup DM, Nagorney DM, Que FG. Surgical treatment of neuroendocrine metastases to the liver: a plea for resection to increase survival. J Am Coll Surg. 2003;197:29-37.

57. Carty SE, Jensen RT, Norton JA. Prospective study of aggressive resection of metastatic pancreatic endocrine tumors. Surgery. 1992;112:1024-32.

58. Wong KP, Tsang JS, Lang BH. Role of surgery in pancreatic neuroendocrine tumor. Gland Surg. 2018;7:36-41.

59. Öberg K. Management of functional neuroendocrine tumors of the pancreas. Gland Surg. 2018;7:20-7.

60. Jin $\mathrm{K}, \mathrm{Xu} \mathrm{J}$, Chen J, Chen M, Chen R, Chen Y, et al. Surgical management for non-functional pancreatic neuroendocrine neoplasms with synchronous liver metastasis: a consensus from the Chinese Study Group for Neuroendocrine Tumors (CSNET). Int J Oncol. 2016;49:1991-2000.

61. Moris D, Tsilimigras DI, Ntanasis-Stathopoulos I, Beal EW, Felekouras E, Vernadakis S, et al. Liver transplantation in patients with liver metastases from neuroendocrine tumors: a systematic review. Surgery. 2017;162:525-36.

62. Lehnert T. Liver transplantation for metastatic neuroendocrine carcinoma: an analysis of 103 patients. Transplantation. 1998;27:1307-12.

63. Sposito C, Droz Dit Busset M, Citterio D, Bongini M, Mazzaferro V. The place of liver transplantation in the treatment of hepatic metastases from neuroendocrine tumors: pros and cons. Rev Endocr Metab Disord. 2017;18:473-83.

64. Shimata K, Sugawara Y, Hibi T. Liver transplantation for unresectable pancreatic neuroendocrine tumors with liver metastases in an era of transplant oncology. Gland Surg. 2018;7:42-6.

65. Le Treut YP, Delpero JR, Dousset B, Cherqui D, Segol P, Mantion G, et al. Results of liver transplantation in the treatment of metastatic neuroendocrine tumors. A 31-case French multicentric report. Ann Surg. 1997;4:355-64.

66. Fernández JA, Robles R, Marín C, Hernández Q, Sánchez Bueno F, Ramírez P, et al. Role of liver transplantation in the management of metastatic neuroendocrine tumors. Transplant Proc. 2003;35:1832-3.

67. Olausson M, Friman S, Cahlin C, Nilsson O, Jansson S, Wängberg B, et al. Indications and results of liver transplantation in patients with neuroendocrine tumors. World J Surg. 2002;26:998-1004.

68. Rossi RE, Burroughs AK, Caplin ME. Liver transplantation for unresectable neuroendocrine tumor liver metastases. Ann Surg Oncol. 2014;21:2398-405.

69. NCCN Clinical Practice Guidelines in Oncology. Neuroendocrine tumors. https://www.nccn.org/professionals/physician_gls/pdf/neuroendocrine.pdf. Accessed May 14, 2018.

70. Lin C, Dai H, Hong X, Pang H, Wang X, Xu P, et al. The prognostic impact of primary tumor resection in pancreatic neuroendocrine tumors with synchronous multifocal liver metastases. Pancreatology. 2018. [Epub ahead of print]

71. Zhou B, Zhan C, Ding Y, Yan S, Zheng S. Role of palliative resection of the primary pancreatic neuroendocrine tumor in patients with unresectable metastatic liver disease: a systematic review and meta-analysis. Onco Targets Ther. 2018;11:975-82.

72. deBaere T, Deschamps F, Tselikas L, Ducreux M, Planchard D, Pearson E, et al. GEP-NETS UPDATE: interventional radiology: role in the treatment of liver metastases from GEP-NETs. Eur J Endocrinol. 2015:172:R151-66.

73. Karabulut K, Akyildiz HY, Lance C, Aucejo F, McLennan G, Agcaoglu O, et al. Multimodality treatment of neuroendocrine liver metastases. Surgery. 2011;150:316-25.

74. Cozzi PJ, Englund R, Morris DL. Cryotherapy treatment of patients with hepatic metastases from neuroendocrine tumors. Cancer. 1995;76:501-9.

75. Christante D, Pommier S, Givi B, Pommier R. Hepatic artery chemoinfusion with chemoembolization for neuroendocrine cancer with progressive hepatic metastases despite octreotide therapy. Surgery. 2008;144:885-93.

76. Akahori T, Sho M, Tanaka T, Nishiofuku H, Kinoshita S, Nagai M, et al. Significant efficacy of new transcatheter arterial chemoembolization technique for hepatic metastases of pancreatic neuroendocrine tumors. Anticancer Res. 2013;33:3355-8.

77. Fiore F, Del Prete M, Franco R, Marotta V, Ramundo V, Marciello F, et al. Transarterial embolization (TAE) is equally effective and slightly safer than transarterial chemoembolization (TACE) to manage liver metastases in neuroendocrine tumors. Endocrine. 2014;47:177-82.

78. Kennedy A, Bester L, Salem R, Sharma RA, Parks RW, Ruszniewski P. Role of hepatic intra-arterial therapies in metastatic neuroendocrinetumours (NET): guidelines from the NET-Liver-Metastases Consensus Conference. HPB (Oxford). 2015;17:29-37.

79. Gupta S. Intra-arterial liver-directed therapies for neuroendocrine hepatic metastases. Semin Intervent Radiol. 2013;30:28-38.
80. Grozinsky-Glasberg S, Kaltsas G, Kaltsatou M, Lev-Cohain N, Klimov A, Vergadis $\checkmark$, et al. Hepatic intra-arterial therapies in metastatic neuroendocrine tumors: lessons from clinical practice. Endocrine. 2018;60:499-509.

81. Okuyama H, Ikeda M, Takahashi H, Ohno I, Hashimoto Y, Mitsunaga S, et al. Transarterial (chemo)embolization for liver metastases in patients with neuroendocrine tumors. Oncology. 2017;92:353-9.

82. Gordon AC, Uddin OM, Riaz A, Salem R, Lewandowski RJ. Making the case: intra-arterial therapy for less common metastases. Semin Intervent Radiol. 2017;34:132-9.

83. Pelage JP, Fohlen A, Mitry E, Lagrange C, Beauchet A, Rougier P. Chemoembolization of neuroendocrine liver metastases using streptozocin and tris-acryl microspheres: Embozar (EMBOsphere + ZAnosaR) study. Cardiovasc Intervent Radiol. 2017:40:394-400.

84. Jia Z, Wang W. Yttrium-90 radioembolization for unresectable metastatic neuroendocrine liver tumor: a systematic review. Eur J Radiol. 2018;100:23-9.

85. Devcic Z, Rosenberg J, Braat AJ, Techasith T, Banerjee A, Sze DY, et al. The efficacy of hepatic $90 Y$ resin radioembolization for metastatic neuroendocrine tumors: a meta-analysis. J Nucl Med. 2014;55:1404-10.

86. Turkmen C, Ucar A, Poyanli A, Vatankulu B, Ozkan G, Basaran M, et al. Initial outcome after selective intraarterial radionuclide therapy with yttrium-90 microspheres as salvage therapy for unresectable metastatic liver disease. Cancer Biother Radiopharm. 2013;28:534-40.

87. Kucuk ON, Soydal C, Lacin S, Ozkan E, Bilgic S. Selective intraarterial radionuclide therapy with Yttrium-90 (Y-90) microspheres for unresectable primary and metastatic liver tumors. World J Surg Oncol. 2011;9:86.

88. Alexander RA, Jensen RT. Pancreatic endocrine tumors. In: DeVita VT, Hellman S, Rosenberg SA, editors. Cancer: principles and practice of oncology. Philadelphia, PA: Lippincott Williams and Wilkins; 2001. p. 1788-813.

89. Valle JW, Eatock M, Clueit B, Gabriel Z, Ferdinand R, Mitchell S. A systematic review of non-surgical treatments for pancreatic neuroendocrine tumours. Cancer Treat Rev. 2014;40:376-89.

90. Appetecchia M, Baldelli R. Somatostatin analogues in the treatment of gastroenteropancreatic neuroendocrine tumours, current aspects and new perspectives. J Exp Clin Cancer Res. 2010;29:19.

91. Strosberg J, Kvols L. Antiproliferative effect of somatostatin analogs in gastroenteropancreatic neuroendocrine tumors. World J Gastroenterol. 2010;16:2963-70.

92. Rinke A, Müller HH, Schade-Brittinger C, Klose KJ, Barth P, Wied M, et al. Placebo controlled, double-blind, prospective, randomized study on the effect of octreotide LAR in the control of tumor growth in patients with metastatic neuroendocrine midgut tumors: a report from the PROMID Study Group. J Clin Oncol. 2009;27:4656-63.

93. Delavault P, Caplin ME, Liyange N, Blumberg J. The CLARINET study: assessing the effect of lanreotide autogel on tumor progression-free survival in patients with nonfunctioning gastroenteropancreatic neuroendocrine tumors. J Clin Oncol. 2012;30:abstr TPS4153.

94. Caplin ME, Pavel M, Ćwikła JB, Phan AT, Raderer M, Sedláčková E, et al. Lanreotide in metastatic enteropancreatic neuroendocrine tumors. N Engl J Med. 2014;371:224-33.

95. Jann H, Denecke T, Koch M, Pape UF, Wiedenmann B, Pavel M. Impact of octreotide long-acting release on tumour growth control as a first-line treatment in neuroendocrine tumours of pancreatic origin. Neuroendocrinology. 2013:98:137-43.

96. Wolin EM. The expanding role of somatostatin analogs in the management of neuroendocrine tumors. Gastrointest Cancer Res. 2012;5:161-8.

97. Ferolla P, Faggiano A, Grimaldi F, Ferone D, Scarpelli G, Ramundo V, et al. Shortened interval of long-acting octreotide administration is effective in patients with well-differentiated neuroendocrine carcinomas in progression on standard doses. J Endocrinol Investig. 2012;35:326-31.

98. Fazio N, de Braud F, Delle Fave G, Oberg K. Interferon-alpha and somatostatin analog in patients with gastroenteropancreaticneuroendocrine carcinoma: single agent or combination? Ann Oncol. 2007;18:13-9.

99. Sorscher S. Metastatic pancreatic poorly differentiated neuroendocrine carcinoma: current treatment considerations. Clin Adv Hematol Oncol. 2013;11:804-5

100. Toumpanakis C, Meyer T, Caplin ME. Cytotoxic treatment including embolization/chemoembolization for neuroendocrine tumours. Best Pract Res Clin Endocrinol Metab. 2007;21:131-44.

101. Kouvaraki MA, Ajani JA, Hoff P, Wolff R, Evans DB, Lozano R, et al. Fluorouracil, doxorubicin, and streptozocin in the treatment of patients with locally 
advanced and metastatic pancreatic endocrine carcinomas. J Clin Oncol. 2004; 22:4762-71.

102. Strosberg JR, Fine RL, Choi J, Nasir A, Coppola D, Chen DT, et al. First-line chemotherapy with capecitabine and temozolomide in patients with metastatic pancreatic endocrine carcinomas. Cancer. 2011;117:268-75.

103. Yamaguchi T, Machida N, Morizane C, Kasuga A, Takahashi H, Sudo K, et al. Multicenter retrospective analysis of systemic chemotherapy for advanced neuroendocrine carcinoma of the digestive system. Cancer Sci. 2014;105:1176-81.

104. Saif MW, Kaley K, Brennan M, Garcon MC, Rodriguez G, Rodriguez T. A retrospective study of capecitabine/temozolomide (CAPTEM) regimen in the treatment of metastatic pancreatic neuroendocrine tumors (pNETs) after failing previous therapy. JOP. 2013;14:498-501.

105. Shi C, Klimstra DS. Pancreatic neuroendocrine tumors: pathologic and molecular characteristics. Semin Diagn Pathol. 2014;31:498-511.

106. Wolin EM. Long-term everolimus treatment of patients with pancreatic neuroendocrine tumors. Chemotherapy. 2015;60:143-50.

107. Yao JC, Shah MH, Ito T, Bohas CL, Wolin EM, Van Cutsem E, et al. Everolimus for advanced pancreatic neuroendocrine tumors. N Engl J Med. 2011;364:514-23.

108. Capurso G, Archibugi L, Delle FG. Molecular pathogenesis and targeted therapy of sporadic pancreatic neuroendocrine tumors. J Hepatobiliary Pancreat Sci. 2015;22:594-601.

109. Leung R, Lang B, Wong H, Chiu J, Yat WK, Shek T, et al. Advances in the systemic treatment of neuroendocrine tumors in the era of molecular therapy. Anti Cancer Agents Med Chem. 2013;13:382-8.

110. Raymond E, Dahan L, Raoul JL, Bang YJ, Borbath I, Lombard-Bohas C, et al. Sunitinib malate for the treatment of pancreatic neuroendocrine tumors. N Engl J Med. 2011;364:501-13.

111. Kennedy AS, Dezarn WA, McNeillie P, Coldwell D, Nutting C, Carter D, et al. Radioembolization for unresectable neuroendocrine hepatic metastases using resin 90Y-microspheres: early results in 148 patients. Am J Clin Oncol. 2008;31:271-9.

112. Filice A, Fraternali A, Frasoldati A, Asti M, Grassi E, Massi L, et al. Radiolabeled somatostatin analogues therapy in advanced neuroendocrine tumors: a single centre experience. J Oncol. 2012;2012:320198.

113. Rossi RE, Massironi S, Spampatti MP, Conte D, Ciafardini C, Cavalcoli F, et al. Treatment of liver metastases in patients with digestive neuroendocrine tumors. J Gastrointest Surg. 2012:16:1981-92.

114. Seregni E, Maccauro M, Coliva A, Castellani MR, Bajetta E, Aliberti G, et al. Treatment with tandem [(90)Y]DOTA-TATE and [(177)Lu] DOTA-TATE of neuroendocrine tumors refractory to conventional therapy: preliminary results. Q J Nucl Med Mol Imaging. 2010;54:84-91.

115. Kwekkeboom DJ, de Herder WW, Kam BL, van Eijck CH, van Essen M, Kooij PP, et al. Treatment with the radiolabeled somatostatin analog [177 Lu-DOTA 0,Tyr3]octreotate: toxicity, efficacy, and survival. J Clin Oncol. 2008;26:2124-30

116. Kwekkeboom DJ, Teunissen JJ, Bakker WH, Kooij PP, de Herder WW, Feelders RA, et al. Radiolabeled somatostatin analog [177Lu-DOTA0,Tyr3] octreotate in patients with endocrine gastroenteropancreatic tumors. J Clin Oncol. 2005;23:2754-62.

\section{Ready to submit your research? Choose BMC and benefit from:}

- fast, convenient online submission

- thorough peer review by experienced researchers in your field

- rapid publication on acceptance

- support for research data, including large and complex data types

- gold Open Access which fosters wider collaboration and increased citations

- maximum visibility for your research: over $100 \mathrm{M}$ website views per year

At BMC, research is always in progress.

Learn more biomedcentral.com/submissions 